\title{
RESPOSTA DE GENÓTIPOS DE CANA-DE-AÇÚCAR À APLICAÇÃO DE INDUTORES DE MATURAÇÃO ( $\left.{ }^{1}\right)$
}

\author{
MARINA MAITTO CAPUTO $\left({ }^{2}\right)$; EDGAR GOMES FERREIRA DE BEAUCLAIR ( $\left.{ }^{2}\right)$; \\ MARCELO DE ALMEIDA SILVA $\left({ }^{3}{ }^{*}\right)$; SÔNIA MARIA DE STEFANO PIEDADE $\left({ }^{4}\right)$
}

\begin{abstract}
RESUMO
O emprego de reguladores vegetais como maturadores da cana-de-açúcar tem sido uma prática bem utilizada, em virtude da necessidade de antecipação da colheita e da otimização do planejamento agrícola. Contudo, com a freqüente disponibilidade de genótipos de cana-de-açúcar pelos programas de melhoramento, pouca informação se tem das interações entre novos genótipos, reguladores vegetais e a qualidade tecnológica. Este estudo objetivou avaliar a resposta de sete genótipos de cana-de-açúcar à aplicação de dois reguladores vegetais quanto à qualidade da matéria-prima. O ensaio foi instalado em março de 2004, no município de Jaú (SP). O delineamento experimental utilizado foi o de blocos casualizados, em parcelas subdivididas, com quatro repetições, constituído pela combinação dos genótipos IAC87-3396, IAC87-3410, IAC89-3124, IAC91-2195, IAC91-5155, PO88-62 e SP80-1842, e de três manejos de desenvolvimento da cultura: sulfometuron-metil, $15 \mathrm{~g}$ i.a. ha ${ }^{-1}$; etefon, $480 \mathrm{~g}$ i.a. ha ${ }^{-1}$ e testemunha. A qualidade tecnológica foi determinada pelos atributos: sólidos solúveis totais ( ${ }^{\circ} B$ Brix) no caldo, sacarose (pol \%) no caldo, pureza do caldo, fibra da cana, açúcares redutores (AR) do caldo e açúcar total recuperável (ATR) no caldo aos 0, 21, 42, 63, 84, 105 e 126 dias após a aplicação (DAA) dos maturadores. Observou-se que o emprego dos maturadores antecipou a colheita em pelo menos 21 dias em relação à testemunha, sendo o etefon indicado para colheita entre 42 e 84 DAA, e o sulfometuron-metil para o período entre 105 e 126 DAA. Os genótipos responderam diferentemente ao emprego dos maturadores etefon e sulfometuron-metil. O genótipo PO88-62 foi mais responsivo ao sulfometuron-metil; IAC87-3396, IAC873410, IAC91-5155 e SP80-1842 ao etefon, e IAC89-3124 e IAC91-2195 responderam a ambos.
\end{abstract}

Palavras-chave: Saccharum spp., maturador, etefon, sulfometuron-metil, atributos tecnológicos.

\section{ABSTRACT \\ RESPONSE OF SUGARCANE GENOTYPES TO THE APPLICATION OF RIPENERS}

The use of plant regulators as sugarcane ripeners has been in order widely used to induce early harvest and optimize crop planning. However, little information exists about the interactions among new released genotypes, plant regulators and technological quality. This study aimed to evaluate the quality response of sugarcane genotypes IAC87-3396, IAC87-3410, IAC89-3124, IAC91-2195, IAC91-5155, PO88-62 and SP80-1842, to the application of ripeners and by three crop management: sulfomethuronmethyl, $15 \mathrm{~g}$ a.i. ha ${ }^{-1}$; ethephon, $480 \mathrm{~g}$ a.i. $\mathrm{ha}^{-1}$ and control. The experiment was installed in March 2004 near Jaú, State of São Paulo, Brazil in split-plot randomized complete blocks, with four replicates. The technological attributes evaluated were: total soluble solids ( ${ }^{\circ}$ Brix) in the juice, sucrose (pol \%) in the

$\left({ }^{1}\right)$ Apresentado pela primeira autora para obtenção do título de Mestre em Agronomia no Programa de Pós-Graduação em Produção Vegetal da Escola Superior de Agricultura "Luiz de Queiroz" (ESALQ-USP). Recebido para publicação em 15 de dezembro de 2005 e aceito em 20 de agosto de 2007.

$\left({ }^{2}\right)$ Departamento de Produção Vegetal, ESALQ/USP, Caixa Postal 9, 13418-900 Piracicaba (SP). Bolsista CNPq. E-mail: mcaputo@esalq.usp.br

$\left({ }^{3}\right)$ APTA Regional Centro-Oeste, Caixa Postal 66, 17201-970 Jaú (SP). E-mail: marcelosilva@apta.sp.gov.br ( $\left.{ }^{*}\right)$ Autor correspondente.

$\left({ }^{4}\right)$ Departamento de Ciências Exatas, ESALQ/USP, Piracicaba (SP).E-mail: soniamsp@esalq.usp.br 
juice, juice purity, cane fiber, reducing sugars (AR) in the juice and recoverable total sugar (ATR) in the juice at $0,21,42,63,84,105$ and 126 days after the application (DAA) of ripeners. It was observed that the use of ripeners anticipated the harvest at least 21 days compared to the untreated control. With ethephon application harvest can be done between 42 and 84 DAA, and with sulfomethuron-methyl between 105 and 126 DAA. The genotypes showed different responses to the application of ripeners. The genotype PO88-62 was highly responsive to sulfomethuron-methyl; IAC87-3396, IAC87-3410, IAC91-5155 and SP801842 to ethephon, and IAC89-3124 and IAC91 2195 to both regulators..

Key words: Saccharum spp., ripener, ethephon, sulfomethuron-methyl, technological attributes.

\section{INTRODUÇÃO}

A importância da cana-de-açúcar é decorrente de sua múltipla utilidade, sendo empregada in natura, sob a forma de forragem, para alimentação animal, ou como matéria- prima para a fabricação de rapadura, melado, aguardente, açúcar e álcool. Seus resíduos também possuem grande importância econômica - o vinhoto é transformado em adubo e o bagaço, em combustível.

A cana-de-açúcar é cultivada principalmente nas regiões tropicais e subtropicais em extensa área, compreendida entre os paralelos $35^{\circ}$ de latitude Norte e Sul. O clima ideal é aquele com duas estações distintas, uma quente e úmida, para proporcionar a germinação, perfilhamento e desenvolvimento vegetativo, seguido de outra fria e seca, para promover a maturação e conseqüente acúmulo de sacarose nos colmos.

Segundo Deuber (1988), o processo de maturação da cana-de-açúcar ocorre naturalmente no início de maio na Região Sudeste do Brasil, atingindo seu clímax em outubro. As condições climáticas existentes, com gradativa queda da temperatura e a diminuição das precipitações pluviais, são as determinantes neste processo. Segundo CAPUTO (2003), o processo de maturação da cana-de-açúcar tem sido estudado em diversos países, sendo de fundamental importância conhecer os atributos do caldo durante o desenvolvimento da planta, dada sua relação com a experimentação agronômica, avaliação rotineira do estádio de maturação ou pagamento da cana pelo teor de sacarose.

CASTRO (1998) definiu que reguladores vegetais são substâncias sintéticas aplicadas exogenamente, que possuem ações similares aos grupos de hormônios conhecidos (auxinas, giberelinas, citocininas, retardadores, inibidores e etileno). Hormônios vegetais são compostos orgânicos, não nutrientes de ocorrência natural, produzidos na planta e que em baixas concentrações $\left(10^{-4} \mathrm{M}\right)$ promovem, inibem ou modificam processos morfológicos e fisiológicos do vegetal; consideram-se retardadores de crescimento as substâncias naturais ou sintéticas que possuem a capacidade de inibir o crescimento do meristema subapical.

As aplicações agrícolas de reguladores vegetais em algumas plantas cultivadas já atingiram estádios de evolução que exigem elevado nível técnico para alcançar maior produtividade. Essas culturas não mais possuem limitações de ordem nutricional e hídrica, além de serem protegidas adequadamente com defensivos. Nessas condições, a economicidade da utilização de tecnologia avançada tem elevado o emprego de reguladores vegetais que podem, freqüentemente, serem compensadores (NICKELL, 1988).

Nesse contexto, o emprego de maturadores químicos, definidos também como reguladores vegetais, na cultura da cana-de-açúcar, destaca-se como uma ferramenta importante (LeiTe, 2005). São produtos aplicados com a finalidade de antecipar o processo de maturação, promover melhorias na qualidade da matéria-prima a ser processada, otimizar os resultados agroindustriais e econômicos e auxiliar no planejamento da safra. Visto que a maturação natural, em início de safra, pode ser deficiente, mesmo em variedades precoces, a aplicação de maturadores em cana-de-açúcar deve objetivar a indução da maturação durante períodos de baixa concentração de sacarose (SubIROS, 1990). O uso de reguladores vegetais deve ser uma prática a ser realizada em curto prazo, para ser substituída, posteriormente, por um programa de manejo de variedades que amadureçam nas épocas desejadas, obtendo-se assim rendimento aceitável durante os períodos críticos da safra.

Época de aplicação dos produtos químicos, doses utilizadas e época de corte da matéria-prima são alguns dos fatores que podem influir na eficiência dos produtos químicos inibidores de florescimento e maturadores da cana-de-açúcar (Leite, 2005). Entretanto, as interações entre esses produtos e genótipos são pouco conhecidas.

O objetivo deste estudo foi avaliar a resposta de sete genótipos de cana-de-açúcar à aplicação de dois reguladores vegetais quanto à maturação e à qualidade da matéria-prima. 


\section{MATERIAL E MÉTODOS}

O ensaio foi desenvolvido na Unidade de Pesquisa e Desenvolvimento de Jaú (SP), da APTA Regional Centro-Oeste, localizada na latitude de $22^{\circ} 17^{\prime} \mathrm{S}$ e longitude $48^{\circ} 34^{\prime} \mathrm{W}$, numa altitude de 580 metros.

O solo da área é Latossolo Vermelho Eutroférrico com A moderado e textura argilosa, segundo a classificação apresentada por PRADO (2003). O clima predominante da região é o Aw (Köppen), com clima seco definido, temperatura média anual de $21,6{ }^{\circ} \mathrm{C}$, umidade relativa média mensal de $70 \%$, com extremos de $99 \%$ em fevereiro e $19 \%$ em agosto. A média pluviométrica anual é de $1.344 \mathrm{~mm}$. Os dados climáticos mensais, referentes às temperaturas máximas, mínimas, precipitação pluvial e o extrato do balanço hídrico (CAD $=100$ $\mathrm{mm}$ ) durante a condução do experimento na safra 2003/2004 são apresentados na figura 1.

A

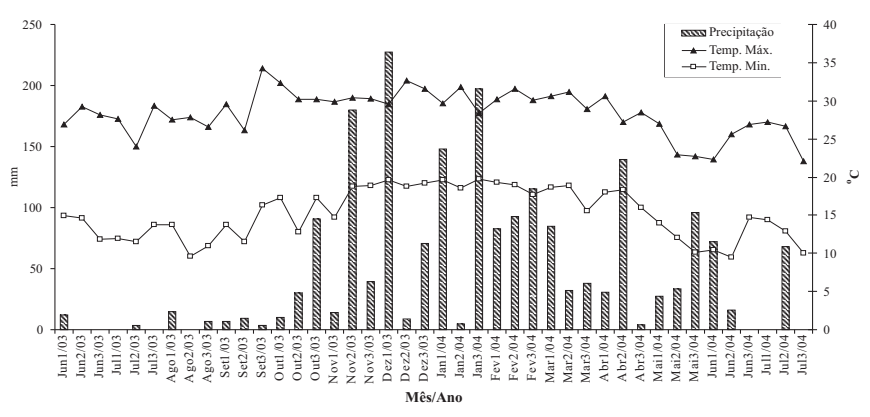

B

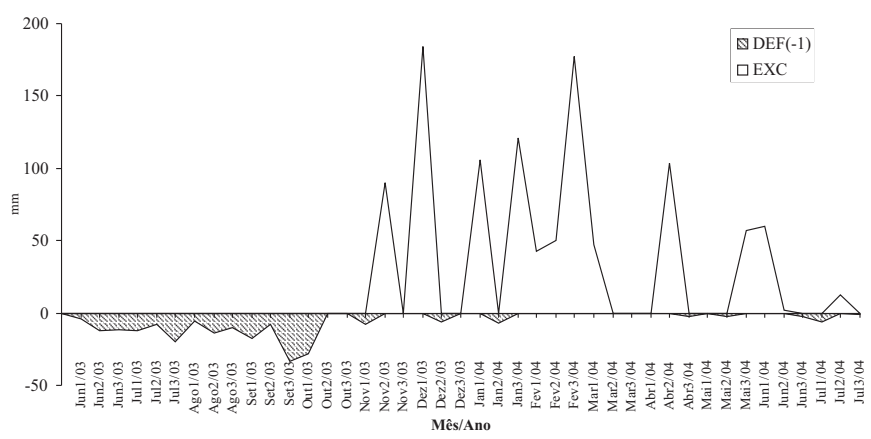

Figura 1. Dados climáticos mensais observados durante o período de realização do experimento. Jaú (SP), safra 2003/2004. (A) temperaturas máximas e mínimas $\left({ }^{\circ} \mathrm{C}\right)$ e precipitação ( $\mathrm{mm}$ ), em escala decendial; (B) extrato do balanço hídrico decendial, $C A D=100 \mathrm{~mm}$ : deficiência e excedente hídrico.
O delineamento experimental utilizado foi o de blocos casualizados, em parcelas subdivididas, com quatro repetições, constituído pela combinação de sete genótipos, diferentes quanto à classificação da maturação, como tratamentos principais: IAC87-3396 (média), IAC87-3410 (tardia), IAC89-3124 (precoce), IAC91-2195 (precoce), IAC91-5155 (média/tardia), PO88-62 (média) e SP80-1842 (precoce), e de três manejos de condução da maturação como tratamentos secundários: sulfometuron-metil, $15 \mathrm{~g}$ i.a. ha ${ }^{-1}$; etefon, $480 \mathrm{~g}$ i.a. ha ${ }^{-1}$ e testemunha, totalizando 21 tratamentos. As parcelas constituíram-se de cinco sulcos de $10 \mathrm{~m}$ de comprimento, espaçados entre si por 1,5 metro.

O plantio da área foi realizado em 26 de julho de 2002 e o primeiro corte ocorreu em 10 de junho de 2003, a fim de realizar o ensaio em cana-soca, para evitar efeitos de acamamento, muito comum na cultura no sistema de cana-planta (CAPUTO, 2003).

A aplicação dos reguladores vegetais ocorreu em 10 de março de 2004. Essa aplicação foi feita com equipamento pressurizado por cilindro de $\mathrm{CO}_{2}$ comprimido, conectado a uma garrafa de PVC, com a calda preparada, ligada aos bicos, um acima de cada linha (tipo Magnum defletor 0,50, de latão, anteriormente testados para igualar a vazão), sustentados por uma barra de ferro de $6,0 \mathrm{~m}$ em forma de U invertido, suspensa por dois indivíduos, caminhando na mesma velocidade.

Um dos indivíduos também conduzia a garrafa que continha a calda do produto químico e a alavanca utilizada para acionar ou interromper a aspersão. A pressão de trabalho foi de $40 \mathrm{lb} \mathrm{pol}^{-2}$ para a vazão de $40 \mathrm{~L} \mathrm{ha}^{-1}$. A concentração da calda foi calculada de acordo com a vazão verificada anteriormente, para obtenção da dose praticada no experimento.

A condição climática, no momento da aplicação, entre 8 e $10 \mathrm{~h}$ e entre 15 e $17 \mathrm{~h}$, era de umidade relativa do ar de $65 \%$ a $91 \%$ e de temperaturas de 18 a $28,5{ }^{\circ} \mathrm{C}$, sem a ocorrência de ventos. Não choveu antes de decorridas 6 horas da aplicação.

Antecedendo a aplicação, realizou-se amostragem de cada parcela para indicação do ponto zero das épocas subseqüentes. As amostragens para avaliação dos atributos tecnológicos ocorreram aos 0 , $21,42,63,84,105,126$ dias após a aplicação dos produtos (DAA). Em cada parcela foi colhido um feixe de dez colmos industriais retirados seguida e aleatoriamente em quatro linhas, consideradas como parcela útil. 
A primeira linha de cada parcela foi desconsiderada como útil, servindo como bordadura entre as parcelas. Posteriormente, encaminharam-se os feixes ao laboratório da Associcana, Jaú (SP), para análise tecnológica, por meio do sistema CONSECANA (2003), para obtenção dos dados de sólidos solúveis totais ( ${ }^{\circ}$ Brix) do caldo, sacarose (pol \%) do caldo, pureza aparente do caldo (\%), fibra da cana (\%), açúcares redutores (AR \%) e açúcar total recuperável (ATR, $\mathrm{kg} \mathrm{t}^{-1}$ ).

Os resultados foram submetidos à análise de variância e utilizando-se o teste de Tukey a 5\% de probabilidade para a comparação de médias.

\section{RESULTADOS E DISCUSSÃO}

Dentre os sete genótipos estudados, a aplicação de etefon diferenciou significativamente do sulfometuron metil e testemunha, proporcionando melhores ganhos de sólidos solúveis para IAC87-3396, IAC87-3410, IAC89-3124, IAC91-2195, IAC91-5155 e SP80-1842 até 84 DAA (Figura 2). A melhor resposta para sulfometuron-metil foi observada para o PO8862 , que superou os demais tratamentos aos 84 e aos 126 DAA. O uso de maturadores induziu o aumento mínimo de $0,9^{\circ} \mathrm{Brix}$, incrementando o teor de sólidos solúveis em relação ao controle, além de antecipar a possibilidade de corte, em experimento com a variedade SP70-1143 (CASTRO et al., 1996).

Verificou-se nos genótipos IAC91-2195, PO8862 e SP80-1842 que a maturação se iniciou aos 42 DAA com a aplicação dos reguladores vegetais. Para o julgamento do estádio de maturação da cana utilizando-se dos sólidos solúveis, o valor ideal para considerá-la madura é de no mínimo $18 \%$ no caldo no início e em todo o decorrer da safra (FERNANDES, 1985). Constatou-se que no tratamento-testemunha, o genótipo IAC91-2195 apenas atingiu estádio de maturação aceitável aos 126 DAA, enquanto PO88-62 e SP80-1842 aos 84 e 63 DAA respectivamente. Portanto, além da antecipar a maturação, o uso dos reguladores vegetais minimizou as diferenças entre períodos de amadurecimento, que podem ser creditadas à característica genética de cada genótipo (Silva, 1996; TANeJA, 1986).

Foram verificados maiores valores de sólidos solúveis no caldo com a aplicação de etefon, diferenciando significativamente dos tratamentos sulfometuron-metil e testemunha, nos genótipos IAC87-3396 e IAC87-3410 dos 21 aos 84 DAA; IAC893124 aos 21 e 84 DAA; IAC91-2195 dos 63 aos 84 DAA; IAC91-5155 dos 42 aos 84, e SP80-1842 dos 21 aos 63 DAA. Por outro lado, o genótipo PO88-62 foi o mais responsivo à aplicação de sulfometuron-metil, obtendo-se dos 21 aos 84 DAA os valores mais altos de sólidos solúveis em relação à testemunha, e o melhor resultado atingido aos $84 \mathrm{DAA}$, quando também se diferenciou significativamente do etefon.
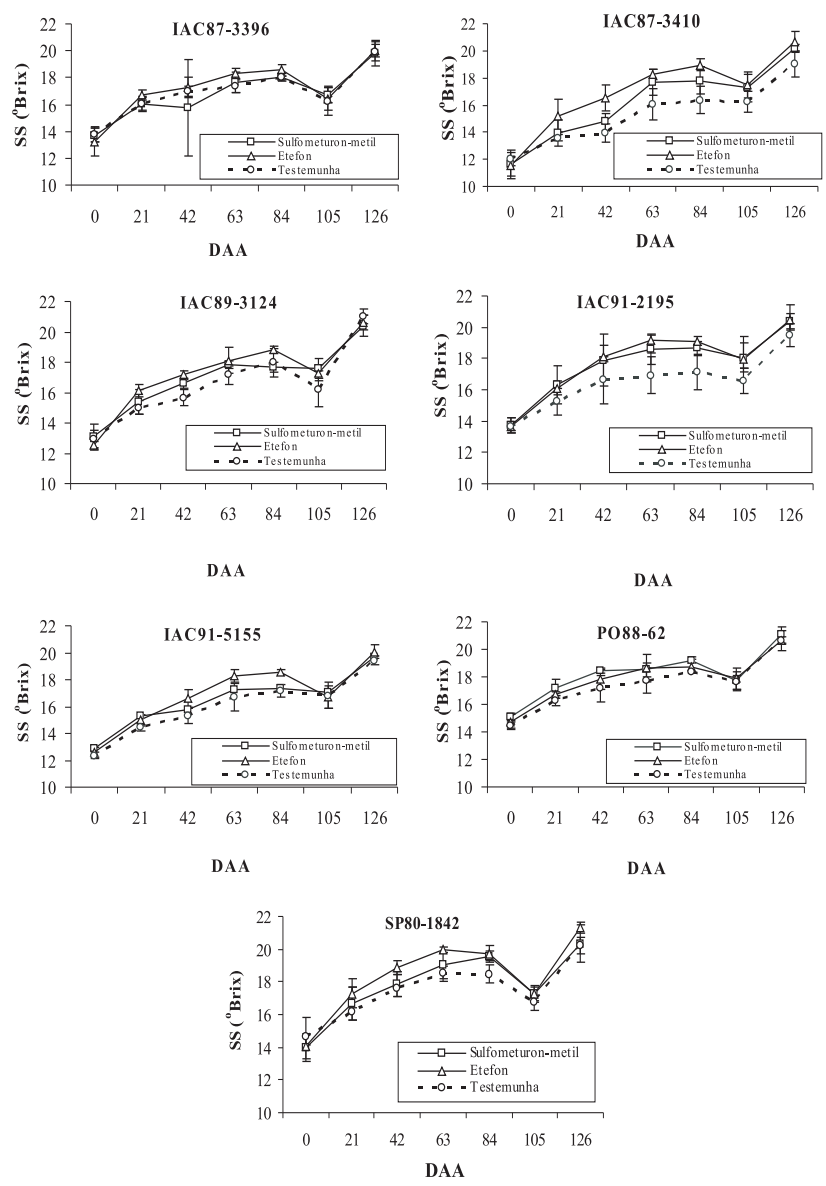

Figura 2. Efeito de reguladores vegetais nos sólidos solúveis (SS) no caldo ( ${ }^{\circ}$ Brix) de sete genótipos de canade-açúcar em função de dias após a aplicação (Cada símbolo indica o valor médio de quatro repetições \pm desvio-padrão).

Os valores de sólidos solúveis em todos os genótipos estudados decresceram na amostragem realizada aos $105 \mathrm{DAA}$, em relação à amostragem aos 84 DAA, nos três tratamentos (etefon, sulfometuronmetil e testemunha) (Figura 2). A ocorrência de precipitações pluviais próxima à amostragem de junho (Figura 1a) proporcionou excedente hídrico (Figura $1 b$ ), o que provavelmente diluiu o teor de sólidos solúveis na solução do caldo da cana-de-açúcar (FERnANDes, 2003). No entanto, os valores de sólidos solúveis voltaram a aumentar aos 126 dias após aplicação dos maturadores, possivelmente em decorrência da manutenção de temperatura mínima (Figura 1a), adequada a maturação, e da diminuição do excedente hídrico em julho (Figura 1b). 
De maneira geral, ao longo das avaliações, a concentração de sacarose (Figura 3) aumentou e verificaram-se melhores resultados nos genótipos tratados com os reguladores vegetais em relação à testemunha. Essa observação evidencia-se a partir dos 42 DAA, mas foi na avaliação de 63 DAA em que se notaram as maiores diferenças entre os tratamentos nos genótipos IAC873410, IAC91-2195, IAC91-5155, PO88-62 e SP80-1842, principalmente no tratamento com etefon cujo ganho variou de 0,76 a 1,15 de pol no caldo, para os genótipos IAC87-3396 e IAC87-3410 respectivamente.
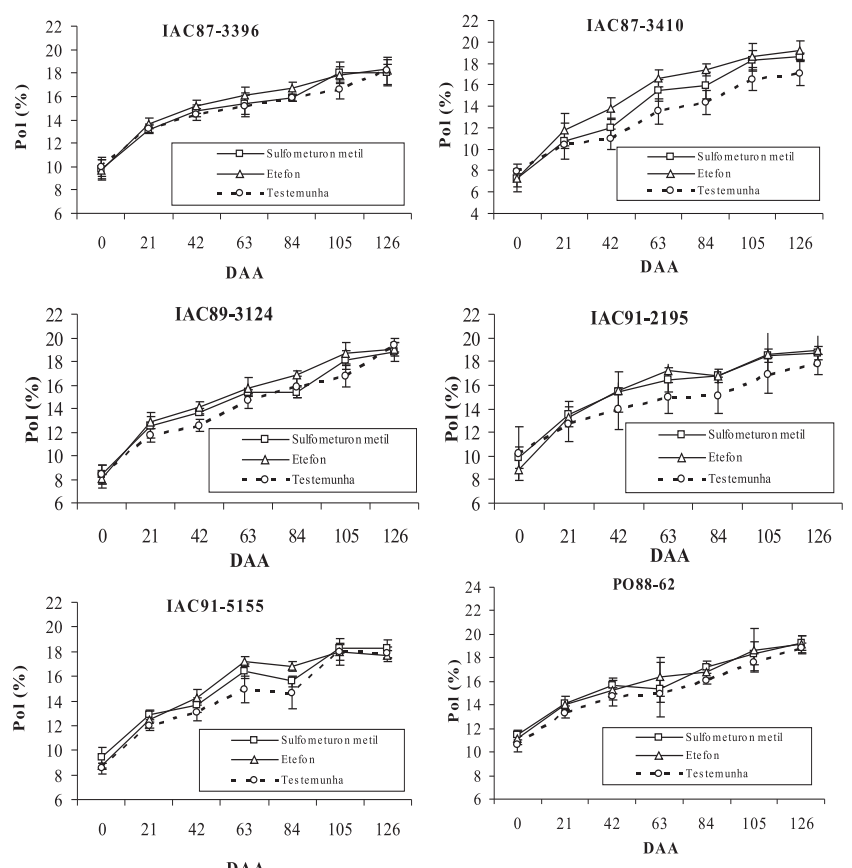

DA

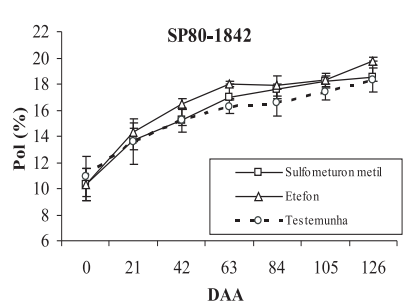

Figura 3. Efeito de reguladores vegetais na pol no caldo (\%) de sete genótipos de cana-de-açúcar em função de dias após a aplicação (Cada símbolo indica o valor médio de quatro repetições \pm desvio-padrão).

Quanto ao tratamento com sulfometuron-metil, de modo geral, os melhores resultados foram obtidos a partir de 105 DAA, apesar de os valores não se diferenciarem significativamente do etefon. Entretanto, constatou-se resposta a partir dos 21 DAA nos genótipos IAC89-3124, IAC91-2195 e PO88-62.

Observaram-se aos 42 DAA, nos genótipos IAC87-3396, IAC91-2195, PO88-62 e SP80-1842, tratados com reguladores vegetais, parâmetros mínimos estabelecidos para pol no caldo para industrialização, de acordo com FeRNANDEs (1985), que adotou valores mínimos entre $14,40 \%$ e $15,30 \%$ de pol no caldo do início para o decorrer da safra. No tratamento testemunha, essa condição foi atingida apenas aos 63 DAA para a maioria dos genótipos. Por esse parâmetro pode-se dizer que o uso dos maturadores poderia antecipar a colheita da maioria dos genótipos em 21 dias. Recentemente, LeITE (2005) também obteve antecipação da colheita em 21 dias na variedade RB855453 utilizando vários produtos, entre eles o etefon e o sulfometuron-metil.

Nenhuma diferença significativa houve entre os maturadores aos 105 DAA, entretanto, ambos diferenciaram-se da testemunha em todos os genótipos, exceto o IAC91-5155. Provavelmente, o período chuvoso próximo a essa amostragem tenha influenciado para que os maturadores se equivalessem (Figura 1 a). Já aos 126 DAA, sem o efeito das chuvas e com temperaturas mínimas em torno de $15{ }^{\circ} \mathrm{C}$, adequadas à maturação, as diferenças entre os tratamentos retornaram, porém com menor intensidade, pois apenas o genótipo IAC87-3410 ainda apresentou efeito entre os três tratamentos.

As observações relatadas neste experimento, sobretudo, no que se refere ao etefon também foram constatadas por LAVANHOLI (2001), com diferenças significativas nas primeiras avaliações (42 e 63 DAA) em relação ao glifosate, mas seu efeito tendeu a desaparecer nas últimas avaliações (105 e 126 DAA), principalmente em relação à testemunha.

FERNANDES (1985) estabeleceu que os valores de pureza do caldo para considerar a cana-de-açúcar madura são de $80 \%$ a $85 \%$ para o início e o decorrer de safra, respectivamente. Nesse experimento constatou-se que o genótipo IAC89-3124, caracterizado como precoce, tratado tanto com etefon quanto com sulfometuron-metil, não apenas atingiu valor de pureza maior que $80 \%$ aos 21 DAA como também se diferenciou da testemunha, sustentando-se assim até os 42 DAA (Figura 4). Os demais genótipos, com exceção do IAC87-3410, também atingiram valores acima de $80 \%$ de pureza nessa época, entretanto, não se diferenciaram da testemunha.

Constatou-se que aos 42 DAA os tratamentos com os dois reguladores diferiram da testemunha nos genótipos IAC87-3410, IAC89-3124 e IAC91-2195. No IAC87-3396, verificou-se diferença apenas com o uso de sulfometuron-metil.

Aos 63 DAA, em todos os genótipos tratados ocorreram valores acima de $80 \%$, chegando a atingir $90 \%$ de pureza. No caso dos genótipos SP80-1842 e IAC87-3410, esse efeito foi obtido com etefon, que os diferenciaram dos demais tratamentos. 

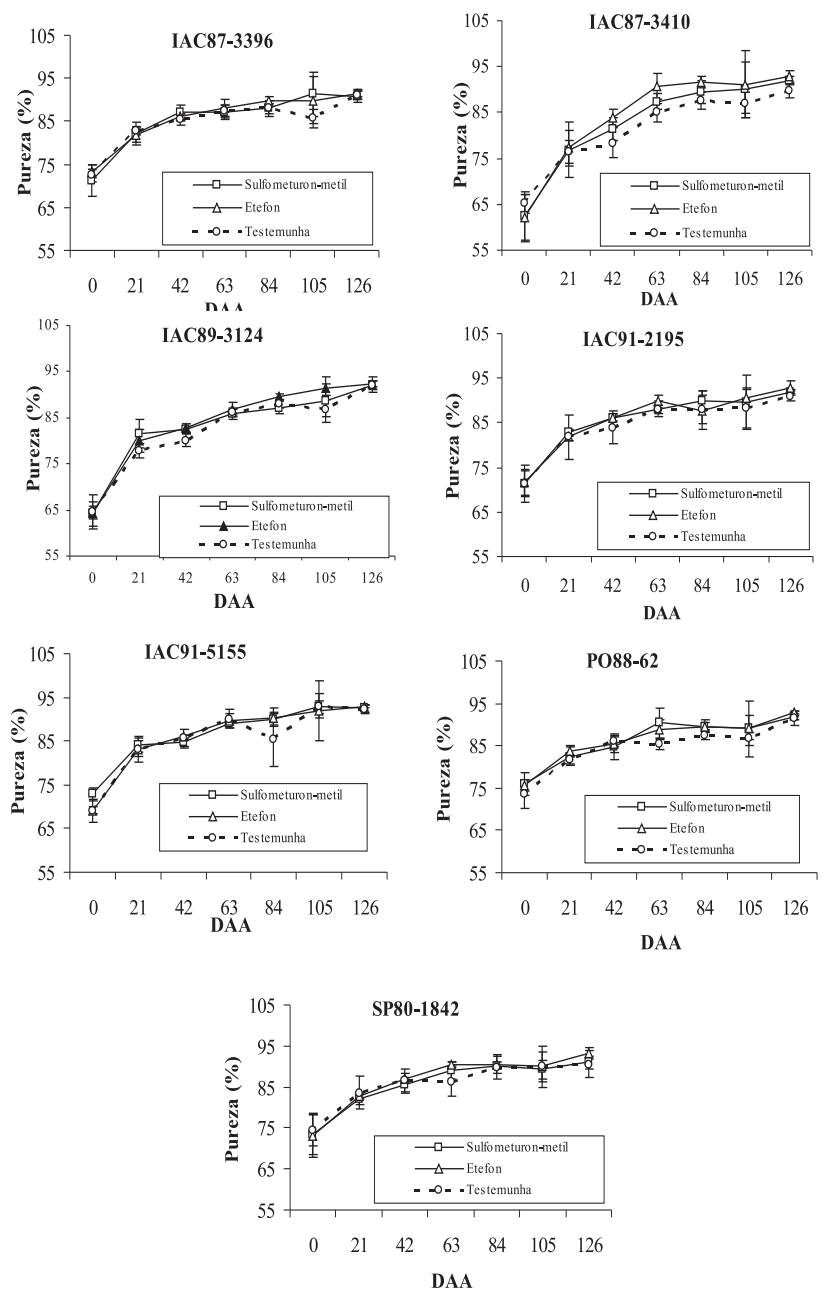

Figura 4. Efeito de reguladores vegetais na pureza do caldo (\%) de sete genótipos de cana-de-açúcar em função de dias após a aplicação (Cada símbolo indica o valor médio de quatro repetições \pm desvio-padrão).

O genótipo PO88-62 acompanhou essa tendência de aumento na pureza, porém com melhor resposta com a aplicação de sulfometuron-metil, que se diferenciou significativamente do etefon e da testemunha aos 63 DAA. Para SILvA (1996), os valores de pureza aparente variam significativamente com o período de análise, além de serem influenciados pelos genótipos. Subiros (1990) observou que nem todos os genótipos de cana-de-açúcar foram responsivos à aplicação de maturadores. Verifica-se, então, que há maior potencialidade de resposta em alguns genótipos, e essa deve ser avaliada quando se pretende realizar o manejo varietal com o emprego desses maturadores.

O etefon proporcionou maiores incrementos de fibra (Figura 5) que a testemunha até os 63 DAA, sendo esse efeito observado nos genótipos IAC87-3396, IAC87-3410, IAC91-2195 e SP80-1842. O genótipo
PO88-62, apesar de especificamente nessa época não ter apresentado diferença entre os tratamentos etefon e testemunha, foi o que mostrou maiores diferenças com o uso desse maturador ao longo das épocas para tal atributo, sendo o genótipo IAC89-3124 o que menos sofreu interferência com a aplicação de etefon ao longo das avaliações. A literatura traz informações de efeitos negativos ou nulos da utilização de etefon sobre a fibra. LeE et al. (1985) mostraram que com o etefon ocorreram efeitos positivos para todos caracteres analisados (pol \% cana, $\mathrm{t}$ cana ha ${ }^{-1}$ e $\mathrm{t}$ pol ha ${ }^{-1}$ ), salvo para a fibra \% cana. CAMPos (1992), com aplicação de etefon (480 g i. a. ha $\left.{ }^{-1}\right)$, constatou que a fibra diminuiu levemente. LeITE (2005) testou sete produtos maturadores, e apenas o etefon não influenciou o atributo fibra. Por outro lado, CASTro et al. (2001) verificaram alteração no teor de fibra da cana com a utilização de etefon somente aos 123 DAA.
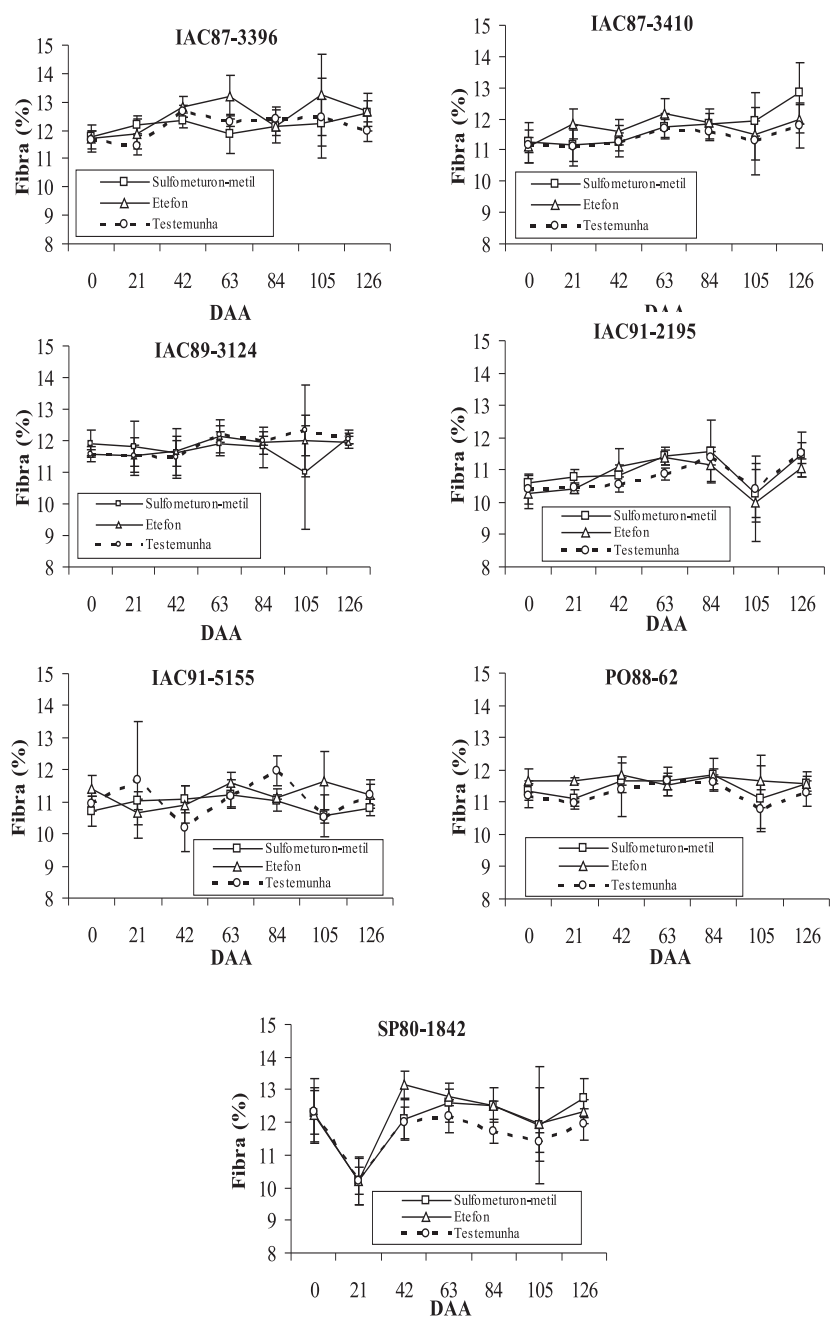

Figura 5. Efeito de reguladores vegetais na fibra na cana (\%) de sete genótipos de cana-de-açúcar em função de dias após a aplicação (Cada símbolo indica o valor médio de quatro repetições \pm desvio-padrão). 
Também para os 63 DAA, o sulfometuron-metil proporcionou aumento de fibra apenas nos genótipos IAC91-2195 e SP80-1842, não se diferenciando do tratamento com etefon. Aos 126 DAA, melhores efeitos do sulfometuron-metil sobre os teores de fibra puderam ser observados para os genótipos IAC873410 e SP80-1842. Entre os genótipos estudados, notou-se no SP80-1842 maior ganho em relação à testemunha, e o IAC91-5155 teve diminuição do teor de fibra quando tratado com sulfometuron-metil. Apesar dessa tendência de efeito mais tardio do sulfometuron-metil sobre os teores de fibra, LeITE (2005) verificou incrementos dos 60 aos 174 DAA na variedade SP80-3280; RAVANELI et al. (2003) constataram que aos 43 dias após aplicação de sulfometuron-metil $\left(15 \mathrm{~g} \mathrm{ha}^{-1}\right)$ houve aumentos significativos nos teores de fibra em relação à variedade SP77-5181.

Conforme o que foi observado, houve pequenas variações de fibra ao longo das épocas amostradas, entre e dentro de genótipos, tanto nos tratados, quanto nos não tratados, provavelmente, porque o atributo fibra é uma característica genética. Segundo CuenYa e Mariotti (1984), nos programas de melhoramento de cana-de-açúcar têm havido dificuldade em obter variedades com elevados pol e fibra, pois quanto maior o teor de sacarose menor o teor de fibra. Portanto, produtos que consigam promover esse efeito duplo na cana-de-açúcar são altamente interessantes.

$\mathrm{Na}$ avaliação feita para açúcares redutores (AR) no caldo (Figura 6), não houve diferenças significativas entre os tratamentos aos $21 \mathrm{DAA}$, com exceção dos genótipos IAC89-3124 e PO88-62. No primeiro, os dois reguladores vegetais diferenciaramse significativamente da testemunha, determinando menores valores de AR, e no segundo, o menor AR foi observado com o emprego de etefon.

Para os genótipos IAC87-3396, IAC87-3410, IAC91-2195 e SP80-1842 o efeito dos produtos iniciouse aos 42 DAA. Dentre estes, a melhor interação com os produtos foi observada para o IAC87-3410, que sustentou os efeitos sobre os AR dos 42 aos 126 DAA. Quanto ao genótipo IAC91-5155, pouco efeito dos produtos foi observado e apenas aos 84 DAA houve diferenças entre a testemunha e os tratamentos com etefon e sulfometuron-metil.

De maneira geral, os valores de AR no caldo foram sempre decrescentes nas avaliações realizadas tanto nas parcelas tratadas quanto nas não tratadas, mostrando que independentemente do emprego dos produtos o processo de maturação estava se desenvolvendo, pois à medida que a cana amadurece, ocorre o acúmulo de sacarose e diminuição dos teores de açúcares redutores nos internódios (AzEVEDo, 1981). No entanto, observouse que nos genótipos IAC87-3410 e SP80-1842, tratados com etefon, a queda dos valores de AR no caldo foi maior do que naqueles tratados com sulfometuron-metil. Exceção para emprego de sulfometuron-metil no genótipo PO88-62, quando aos 63 DAA houve queda maior nos valores em relação ao etefon. Tais resultados concordam com estudos realizados por CASTRO et al. (1996), cujos relatos atestam que o etefon e o sulfometuron-metil induziram a diminuição dos açúcares redutores.

Durante o período de avaliações verificouse que os valores de ATR (Figura 7) foram crescentes, no entanto as diferenças entre as médias começaram a ser significativas a partir dos 42 DAA, em relação aos genótipos tratados e a testemunha.
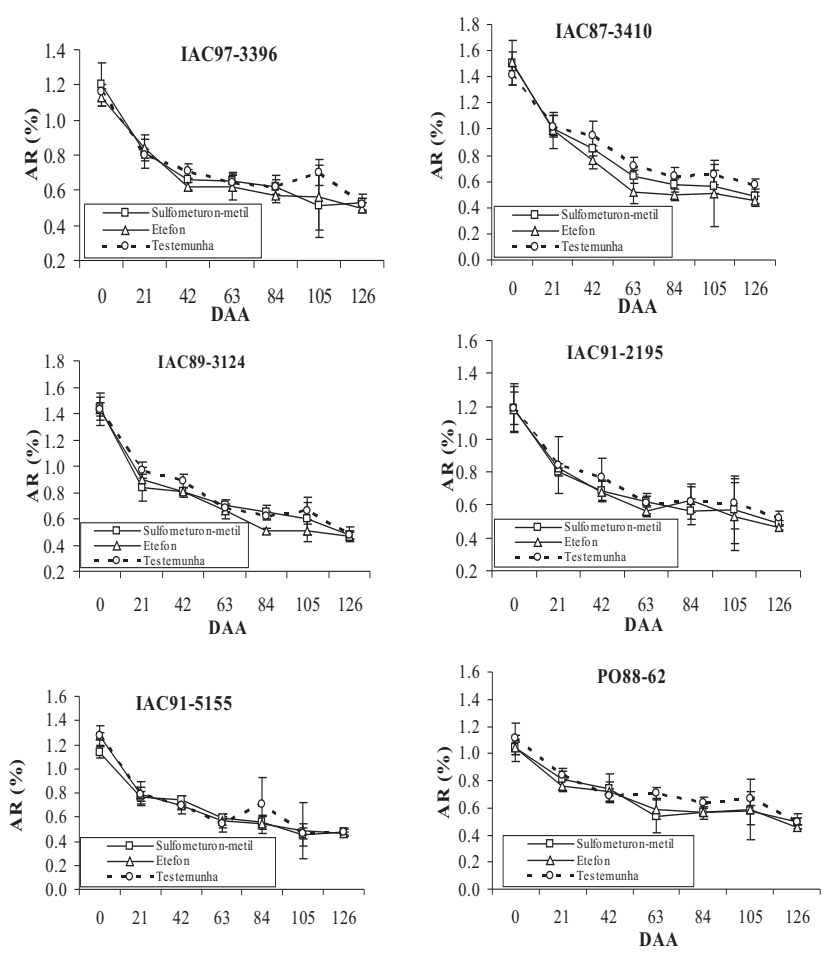

DAA

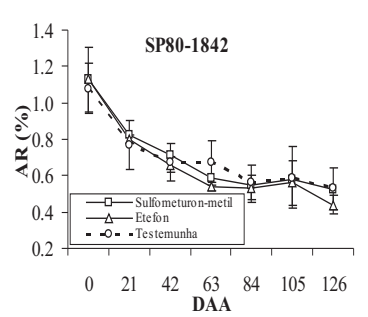

Figura 6. Efeito de reguladores vegetais nos açúcares redutores (AR) no caldo (\%) de sete genótipos de canade-açúcar em função de dias após a aplicação. (Cada símbolo indica o valor médio de quatro repetições \pm desvio-padrão). 

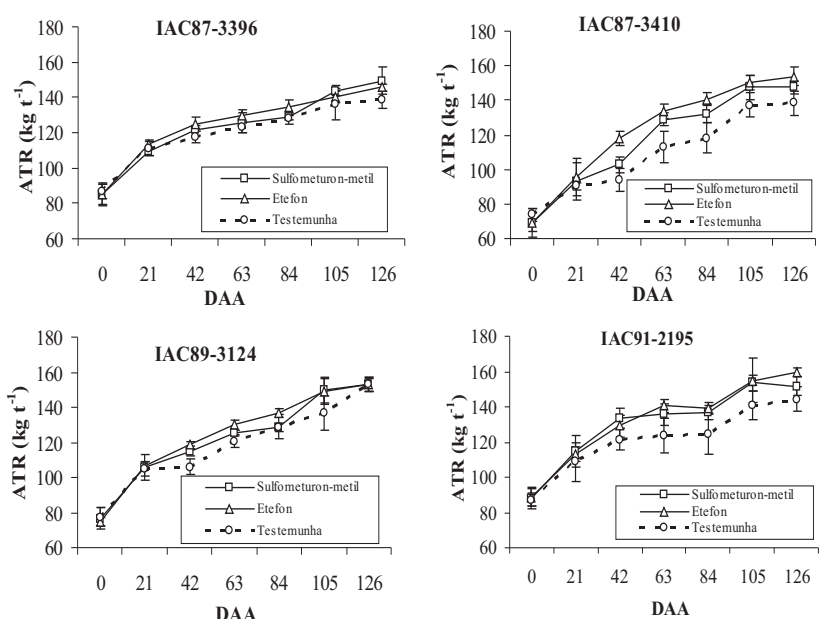

DAA
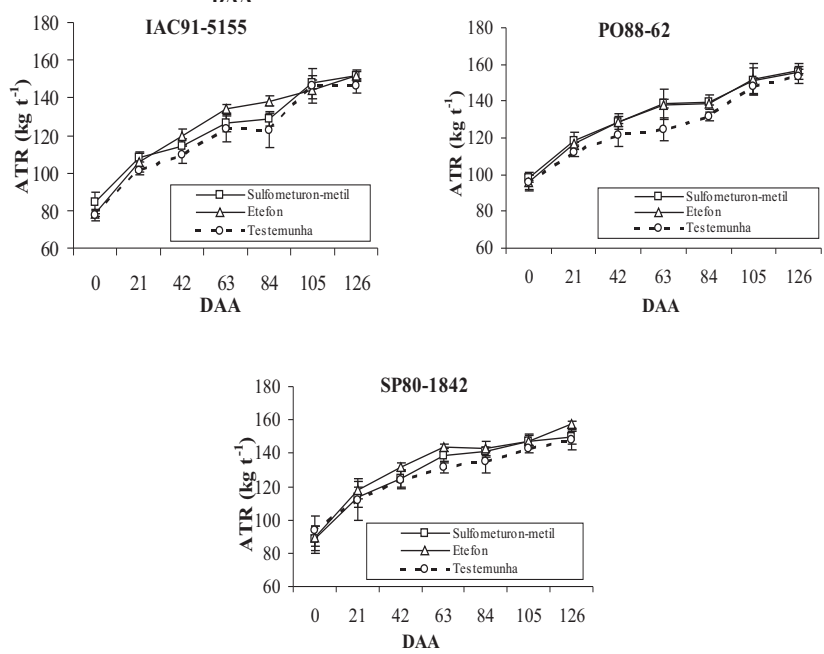

Figura 7. Efeito de reguladores vegetais no açúcar total recuperável (ATR) na cana $\left(\mathrm{kg} \mathrm{t}^{-1}\right)$ de sete genótipos de cana-de-açúcar em função de dias após a aplicação (Cada símbolo indica o valor médio de quatro repetições \pm desvio-padrão).

Nos genótipos de maturação precoce IAC893124 e IAC91-2195, indicados para colheita entre abril e maio, os valores médios de ATR se diferenciaram significativamente entre tratamentos aos 42 e 63 DAA, com vantagem para o etefon, seguido pelo sulfometuron-metil e depois da testemunha. Já para o PO88-62, os dois produtos maturadores tiveram comportamento semelhante dos 21 aos 84 DAA, não se diferenciando entre si, mas da testemunha. No entanto, para o SP80-1842, apenas aos 63 DAA houve diferenças significativas entre os tratamentos, também com vantagem para o etefon; e dos 84 aos 126 DAA os dois produtos se igualaram significativamente, diferenciando da testemunha.

Em relação ao efeito dos produtos sobre o genótipo de maturação média, IAC87-3396, observouse que o etefon ocorreramvalores médios de ATR maiores entre os 42 e 84 DAA em relação às canas tratadas com sulfometuron-metil, igualando-se aos
105 DAA; aos 126 DAA, houve inversão do efeito se inverteu com vantagem para o sulfometuron-metil.

Nos genótipos de maturação média/tardia, IAC 87-3410 e IAC91-5155, observaram-se comportamentos semelhantes com valores médios de ATR maiores para plantas tratadas com etefon em relação às tratadas com sulfometuron-metil, principalmente dos 42 aos 84 DAA. LAVANHOLI (2001), em experimento realizado com a variedade tardia SP70-1143, observou que os tratamentos com etefon proporcionaram maiores valores médios de ATR entre 67 a 95 DAA.

Nascimento e Gheller (2005), trabalhando com duas variedades de maturação distintas - RB72454 (tardia) e RB835486 (precoce) - e três reguladores vegetais, obtiveram ganhos expressivos de ATR, que variaram de 5 a $7 \mathrm{~kg}$ e de 4 a $11 \mathrm{~kg}$ respectivamente. Neste ensaio, também se verificaram ganhos diferenciados, a exemplo do genótipo IAC89-3124 que variou de 4 a $7 \mathrm{~kg}$ de ATR por tonelada de colmo, e de 12 a $15 \mathrm{~kg}$ de ATR por tonelada de colmo para o IAC87-3410 aos 63 DAA.

De maneira geral, em todos os genótipos tratados, a qualidade tecnológica dos colmos, decorrentes da melhor expressão do atributo ATR, tornou-se superior em relação às plantas não tratadas.

\section{CONCLUSÕES}

1. O emprego dos maturadores antecipa a colheita de cana-de-açúcar em pelo menos 21 dias, em relação à testemunha, podendo-se efetuá-la entre 42 e 84 dias após a aplicação do etefon e entre 105 e 126 dias após a aplicação de sulfometuron-metil.

2. Nos genótipos observam-se respostas diferentes aos maturadores. Em relação ao teor de sacarose (pol no caldo), importante característica tecnológica, o genótipo PO88-62 foi mais responsivo ao sulfometuron-metil; IAC87-3396, IAC87-3410, IAC91-5155 e SP80-1842 ao etefon, e IAC89-3124 e IAC91-2195 foram responsivos a ambos.

\section{AGRADECIMENTOS}

À DuPont pelo suporte financeiro. Ao consultor Engenheiro Agrônomo Renato Sanomya, pela assessoria na utilização dos produtos. À Associcana, Jaú (SP), pela realização das análises tecnológicas. Aos técnicos agrícolas Valdir Lotti e João Paulo Nascimento pelo apoio no experimento. À senhorita Aline Vanessa Zambello pela digitação do manuscrito. À FUNDAG pela administração dos recursos financeiros 


\section{REFERÊNCIAS}

AZEVEDO, H.J. Fisiologia da cana-de-açúcar. Araras: Programa Nacional de Melhoramento da Cana-de-açúcar, 1981. 108p. (Apostila)

CAMPOS, M.S. A utilização do Ethrel em escala comercial na Açucareira Corona S/A - Usina Bonfim. In: ENCONTRO RHODIA DE CANA-DE-AÇÚCAR, 2., 1992, São Paulo. Anais... São Paulo: Rhodia, 1992. p. 93-104.

CAPUTO, M.M. Efeito do tombamento nas características tecnológicas e biométricas de variedades de cana-de-açúcar. 2003. 63p. Monografia (Trabalho de graduação em Agronomia) - Faculdade de Ciências Agrárias e Veterinárias - UNESP, Jaboticabal.

CASTRO, P. R. C. Utilização de reguladores de vegetais na fruticultura, na olericultura e em plantas ornamentais. Piracicaba: DIBID/ESALQ/USP, 1998. 91p. (Boletim Série Produtor Rural)

CASTRO, P.R.C.; OLIVEIRA D. A.; PANINI E. L. Ação do sulfometuron-metil como maturador da cana-de-açúcar. In: CONGRESSO NACIONAL DA SOCIEDADE DOS TÉCNICOS AÇUCAREIROS DE ALCOOLEIROS DO BRASIL, 6., 1996, Maceió. Anais... Maceió: Sociedade dos Técnicos Açucareiros e Alcooleiros do Brasil, 1996. p. 363-369.

CASTRO, P.R.C.; MIYASAKI, J.M.; BEMARDI, M.; MARENGO, D.; NOGUEIRA, M.C.S. Efeito do ethephon na maturação e produtividade da cana-de-açúcar. Revista de Agricultura, Piracicaba, v. 76, n. 2, p. 277-290, 2001.

CONSECANA. Manual de Instruções. 4 ed. Piracicaba: Conselho dos Produtores de Cana-de-Açúcar, Açúcar e Álcool do Estado de São Paulo, 2003. 115p.

CUENYA, M.I.; MARIOTTI, J.A. Seleccion por erectilidad en progenies hibridas de caña de azucar (Saccharum spp.). In: CONGRESSO NACIONAL DA SOCIEDADE DOS TÉCNICOS AÇUCAREIROS DE ALCOOLEIROS DO BRASIL, 3., 1984. São Paulo Anais... São Paulo: Sociedade dos Técnicos Açucareiros e Alcooleiros do Brasil, 1984, p. 226-235.

DEUBER, R. Maturação da cana-de-açúcar na região Sudeste do Brasil. In: SEMINÁRIO DE TECNOLOGIA AGRONÔMICA, 4., 1988, Piracicaba. Anais... Piracicaba: Copersucar, 1988. p. 33-40.

FERNANDES, A.C. Autorização da colheita da cana-de-açúcar. In: SEMANA DE FERMENTAÇÃO ALCOOLICA "JAIME ROCHA DE ALMEIDA",4., 1985, Piracicaba. Anais... Piracicaba: Escola Superior de Agricultura "Luiz de Queiroz", USP, 1985. p.12-21.

FERNANDES, A.C. Cálculos na agroindústria de cana-deaçúcar. 2.ed. Piracicaba: STAB, 2003. 240p.

LAVANHOLI, M.G.D.P. Aplicação de ethephon e imazapyr como inibidor de florescimento em cana-de-açúcar (Saccharum spp., var SP70-1143). 2001. 210p. Tese (Doutorado) - Faculdade de Ciências Agrárias e Veterinárias - UNESP, Jaboticabal.
LEE, T.S.G.; SILVA, M.R.; IAIA, A.M.; MAGALHÃES, P.M.; PERUSSI, E.M. Controle de florescimento da cana-de-açúcar através do emprego de produtos químicos. Revista STAB - Açúcar, Álcool e Subprodutos, Piracicaba, v. 3, n. 3, p.1721, 1985.

LEITE, G.H.P. Maturação induzida, alterações fisiológicas, produtividade e qualidade tecnológica da cana-de-açúcar (Saccharum officinarum L.). 2005, 141p. Dissertação (Mestrado em Produção Vegetal) - Faculdade de Ciências Agronômicas - UNESP, Botucatu.

NASCIMENTO, R.; GHELLER, A.C.A. Resultados da aplicação de maturadores vegetais em cana-de-açúcar, variedades RB72454 e RB835486 na região de Araras, SP. Disponível em: http://www.propg.ufscar.br/publica/4ic/ixcic/UFSCar/ Agrarias/879-nascimento.htm.> Acesso em: 7 nov. 2005.

NICKELL, L.G. Plant growth regulating chemicals. Chicago: CRC Press, 1988, v.1/2., 256p.

PRADO, H. Solos do Brasil: gênese, morfologia, classificação, levantamento e manejo. 3.ed. Piracicaba: H. do Prado, 2003. 275p.

RAVANELI, G. C.; GUIMARÃES, E.R.; VINHAS, T. DURIGAN, A.M.P.R.; MUTTON, M.A; MUTTON M.J.R. Parâmetros tecnológicos da cana-de-açúcar (Saccharum spp L.- var SP775181) tratada com sulfometuron-metil. In: CONGRESSO BRASILEIRO DE FISIOLOGIA VEGETAL, 9., 2003. Atibaia. Anais... Atibaia: Brazilian Journal of Plants Physiology, 2003. v. 15. p.347.

SILVA, M.A. Época de amostragem na seleção e qualidade tecnológica de clones de cana-de-açúcar (Saccharum spp.). 1996. 159p. Tese (Doutorado) - Faculdade de Ciências Agronômicas - UNESP, Botucatu.

SUBIROS, J.F. Efecto de la aplicación glifosato como madurador en tres cultivares de caña de azúcar. Turrialba, San Jose, v. 40, n. 4, p.527-534, 1990.

TANEJA, A. D. Effect of crop age on the quality early, mid and late maturing varieties of sugarcane. Indian Sugar, Calcutá, v.36, p155-59, 1986. 